\title{
Criar paisajes vivos, una manera de aprehender y (re) pensar la ciudad*
}

\begin{tabular}{|l|l|}
\hline Fecha de recepción: 14 de abril de 2016 Fecha de aceptación: 19 de julio de 2016 Disponible en línea: 30 de octubre de 2016 \\
\hline Karina Borja \\
\hline Doctora en Estética, Valores y Cultura UPV (Universidad del País Vasco) \\
\hline Participante de una estancia de posdoctorado en la UNAM (Universidad Nacional Autónoma de México). \\
\hline Docente-investigadora de la Facultad de Arquitectura, Diseño y Artes \\
\hline de la PUCE (Pontificia Universidad Católica del Ecuador) & kborja@puce.edu.ec karinab81@hotmail.com \\
\hline
\end{tabular}

Resumen Los paisajes vivos propuestos desde la interculturalidad implican una manera de revitalizar los principios del pensamiento andino para comprender y aprehender la compleja realidad de una ciudad como Quito, donde perviven rezagos de culturas ancestrales. La idea es recuperar la emoción estética de un lugar — en este caso del barrio San Isidro de El Inca-; generar un continuo aprendizaje vivencial; y revalorar los ritos, mitos y celebraciones, con el fin de criar paisajes sanos. Esto conlleva un reconocimiento explícito de la multidimensionalidad (sociopolítica, económica, cultural y espacial) de un barrio o una ciudad en relación con su territorio. Se busca cuestionar la forma de hacer ciudades para construir plataformas que susciten diálogos y discusiones políticas.

Palabras clave Aprendizaje vivencial; paisaje intercultural; paisajes vivos

\footnotetext{
Este es un artículo de reflexión sobre la propuesta de la tesis doctoral Criar paisajes vivos; una manera de aprehender los paisajes urbanos andinos. El caso de San Isidro de El Inca, presentada en la Universidad del País Vasco, Donostia, Guipúzcoa, España, en junio de 2012. Ha sido realizado durante una estancia posdoctoral (2015-2016) en el Programa de Posgrado en Urbanismo de la UNAM, bajo la tutoría del doctor Héctor Quiroz.
}

Cómo citar este artículo: Borja, K. (2016). Criar paisajes vivos, una manera de aprehender y (re) pensar la ciudad. Cuadernos de Vivienda y Urbanismo, 9(18), 276-291. http://dx.doi.org/10.11144/Javeriana.cvu9-18.cpvm 


\section{Raising Alive Landscapes: A Way to Learn and Rethink the City}

Abstract The live landscapes proposed from the inter-cultural view point imply a way of rethinking revitalizing the principles of the Andean thought to understand and learn the complex reality of a city such as Quito in which live traces of their ancestral cultures. The idea is to try to recuperate the esthetic emotion, in this case the barrio of San Isidro of El Inca, to generate a continued lively training of the places, re-evaluate the rites, myths and celebrations with the end of raising healthy landscapes. This implies an explicit recognition of the complex multi-dimensionality: socio-political, economic, cultural and spacial of the neighborhood, a city in relation to its territory. It supposes to question the city making shape with the finality of building platforms that provoque dialogues and political discussion.

Keywords Experiential learning; inter-cultural landscape; live landscapes

\section{Criar paisagens vivas, uma maneira de prender e (re) pensar a cidade}

Resumo As paisagens vivas propostas por uma visão intercultural implicam em uma maneira de refletir, revitalizando os princípios do pensamento andino para compreender e apreender a complexa realidade de uma cidade como Quito, que sobrevive dos restos de suas culturas ancestrais. A ideia é tentar recuperar a emoção estética, neste caso, o bairro de San Isidro del Inca, gerar uma contínua aprendizagem vivencial dos lugares, revalorizar os ritos, mitos e celebraçóes com o objetivo de criar paisagens saudáveis. Isto implica em um reconhecimento explícito da complexa multidimensionalidade: sócio-política, econômica, cultural e espacial de um bairro, uma cidade em relação ao seu território. Pressupóe questionar a forma de fazer as cidades com a finalidade de construir plataformas que proporcionem diálogos e discussóes políticas.

Palavras chave Aprendizagem experiencial; paisagem intercultural; paisagens vívidas 


\section{Introducción}

En el proceso de investigación de los paisajes urbanos emergieron como hechos vivenciales las fiestas que se celebran en algunos barrios de la ciudad andina de Quito, especialmente en el lugar seleccionado para el estudio: el barrio San Isidro de El Inca. Uno de los hallazgos fue la yumbada, una danza que rememora las relaciones de los habitantes de Quito con los de las tierras bajas. Para dar inicio a estas festividades, desde las vísperas, los danzantes, en este caso $y u m b$ os $^{1}$, se juntan y participan activamente durante los tres días de festejo, en un contexto netamente urbano residencial, muy ajeno al que normalmente se piensa para este tipo de ritualidades.

Figura 1.

Visperas de la yumbada

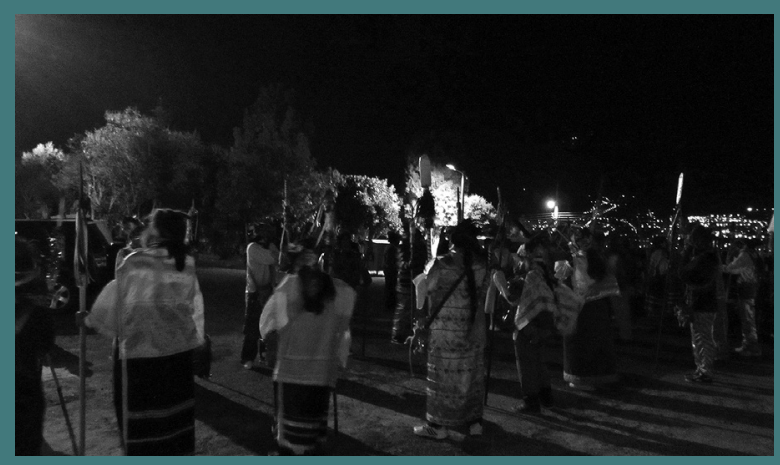

Fuente: Borja (2015)
Estas fiestas se celebran por la Virgen de las Mercedes, alrededor del 24 de septiembre, a la vez que rememoran la ceremonia ancestral del equinoccio, el colla raymi ${ }^{2}$, y el período de siembra en los andes septentrionales. La fiesta es un indicio de la pervivencia de la cultura ancestral en esta comunidad. Se trata de hechos difíciles de aprehender con el estudio del paisaje urbano, el tema inicial de interés, que resulta insuficiente en estos casos (Borja, 2012; 2015).

Esto marcó un cambio de dirección en la investigación. Fue necesario introducirse en los mundos que afloran en las festividades, y surgió la necesidad de hablar de otros paisajes, ir a su origen y comprender que la mayoría de estos sucesos son actos de resistencia. Este hito en la investigación fue asumido con una mirada intercultural y, por tanto, de acercamiento al pensamiento andino, cuyos principios están claramente vigentes en estas manifestaciones.

Ahí perviven principios fundamentales de la cultura andina, como el ayni (reciprocidad) por medio del waki-waki (prestamanos), estrategia fundamental para la realización de estos eventos. Con estas fiestas se celebra a la Pachamama (madre tierra), pero también la convivencia y la relacionalidad, principios fundamentales del

1 Los yumbos son un grupo de habitantes de la ceja de montaña de la cordillera occidental. En la época precolombina estuvieron ubicados al norte y al sur de la ciudad de Quito. Hasta inicios de la Colonia se trataba de un grupo especializado en la comercialización de los productos de tierras bajas (cálidas) y tierras altas (frías). Las últimas investigaciones arqueológicas han demostrado los avances de su cultura, por lo que algunos investigadores los denominan "nación yumba" (Jara, 2007).

2 Fiesta dedicada a la colla o coya, esposa del inca, y también a la Luna (Quilla), principal divinidad femenina. Se efectuaba durante el equinoccio de septiembre. Actualmente se la está reinsertando o recuperando nuevamente como tal. 
pensamiento andino. Sin embargo, estos hechos festivos son ignorados en la planificación del gobierno local ${ }^{3}$, e inclusive por los otros pobladores del barrio, pese a que son profundamente vivenciales y promueven una movilización y organización que no se logran con ninguna otra actividad barrial y comunitaria.

A partir de estas reflexiones, realizadas durante la tesis doctoral, nace la noción de los paisajes vivos como un concepto intercultural; una manera de dar cuenta de la compleja realidad de una ciudad donde subsisten rezagos de culturas ancestrales en medio del discurso de un mundo globalizado. Tal y como se proponen, estos paisajes vivos parten de un reconocimiento explícito de la multidimensionalidad (sociopolítica, económica, cultural y espacial) de la ciudad de Quito, complejidad que es similar a la de muchas otras ciudades de América Latina.

La idea es utilizar la noción de paisajes vivos para 1) comprender a los paisajes como sujetos; 2) recuperar la emoción estética que produce el barrio; 3) celebrar el lugar donde uno vive; 4) generar un continuo aprendizaje vivencial sobre los lugares $^{4}$ (Augé, 1992); y 5) ir hacia la convivencialidad 5 como lo propone Ivan Ilich (1978). Todo esto con el fin de acercarse a las diversas maneras de criar paisajes sanos. La investigación en la que se basa este artículo contempló una revisión bibliográfica profunda; recoge momentos etnográficos importantes que fueron sometidos a un análisis riguroso para encontrar posibles y distintas interpretaciones de los múltiples simbolismos y metáforas del tejido social; e incluye recorridos y observaciones que permitieron analizar la estructura y los espacios urbanos en relación con su gente.

El objetivo de este artículo es poner en discusión las bases conceptuales de esta investigación, que supone un cuestionamiento a las formas de hacer ciudad, y reconocer principios importantes de nuestras culturas ancestrales (lo que corresponde a la parte conceptual de la tesis doctoral). En la actualidad está en elaboración un libro y otros artículos en los que se expondrán los demás elementos constitutivos de la propuesta de paisajes vivos. Por lo pronto, para este artículo parto de la pregunta clave, ¿qué son los paisajes vivos?, para luego plantear la cuestión de por qué hablar de ellos, el significado de los paisajes andinos, y las reflexiones sobre una nueva forma de pensar. Por último, propongo el aprendizaje vivencial de la ciudad desde una mirada intercultural.

\section{Contenido}

\section{¿Qué son los paisajes vivos?}

Los paisajes vivos, propuestos como un concepto intercultural, comprenden la idea 'yo soy paisaje' y 'nosotros somos paisaje', así como la presunción de que estos tienen sentimientos (aman) y sabiduría (piensan). Son criados por nosotros y, a la vez, nos crían, en una correlación del paisaje con la vida. Se los nombra en plural porque existen diferentes paisajes, cada uno con su carácter, cualidades y sentimientos, pues han sido criados de distinta forma, en varios lugares, por otros

3 Un ejemplo de ello es la falta de apoyo (económico y logístico) a estos danzantes y, como parte de esto, la ausencia de espacios públicos ad hoc para el desarrollo de las fiestas en este barrio y los barrios colindantes, pese a que en la Constitución del Ecuador vigente (2008) y en la Ordenanza 260 del Distrito Metropolitano de Quito se reconoce el "patrimonio intangible constituido por las diversas expresiones socio-culturales" ( DMQ, 2008, p. 2) y se expresa el deber de preservarlas.

4 Los lugares, en el sentido propuesto por Marc Augé (1992), se entienden como "Ios espacios con los que los individuos se identifican y, por tanto, generan lazos" (p. 41).

5 La convivencialidad es un concepto desarrollado por Ivan llich (1978) que contempla lo inverso a la productividad industrial. Apunta a reemplazar el dominio de la herramienta sobre el ser humano para defender valores esenciales. Considera que la herramienta justa "responde a tres exigencias: es generadora de eficiencia sin degradar la autonomía personal; no suscita ni esclavos, ni amos; expande el radio de acción personal” (p. 28). 
runas (seres humanos). El paisaje natural contiene el equilibrio de la energía de la sabia naturaleza en su máxima expresión y extensión. El paisaje urbano es generado con una manera diferente de criar (Borja, 2012).

Según el pensamiento andino, la relación que se establece con el paisaje es de sujeto-sujeto, en la medida en que este está vivo. Esta relación es simbólica y presencial, está siendo y haciéndose permanentemente, es lenguaje y comunicación. Por tanto, el paisaje nos educa, a la vez que lo educamos, en el sentido autopoyético de enseñarse. La tensión que viven los paisajes reales e imaginarios genera nuevas armonías o desarmonías. Una correlación adecuada proporciona salud, educación, vivienda, hábitat; marcha hacia el crecimiento en armonía y el buen vivir ${ }^{6}$ (sumak kawsay) (Acosta, 2013). En caso contrario, provoca la destrucción, el caos social.

Estos paisajes tienen que ver con el concepto andino pacha, que define el cosmos y las relaciones con él mediante la anidación ${ }^{7}$ y sus cinco dimensiones. La primera dimensión se conoce como la paridad y se refiere a la convivencia de un ser humano con su par. La segunda dimensión se llama comunidad y define el plano donde viven los pares, como comunidad, dentro de las familias y como parte del medio (topografía, paisaje, etc.); esta dimensión anida a la primera. La tercera dimensión es la relación de la comunidad con el ambiente, donde entran también las relaciones con los paisajes, que es otro plano o campo de prácticas de la unidad ser humano-naturaleza, y que engloba ámbitos como la agricultura, la ciencia, la producción de alimentos, el festejo y todas las actividades comunales; esta tercera dimensión anida a las dos anteriores. La cuarta dimensión crea un plano donde son anidadas las tres primeras e implica la armonización por medio del carácter vinculante: la complementariedad, la proporcionalidad, la reciprocidad entre el runa, la comunidad y el ambiente. Finalmente, la quinta dimensión se puede entender como la anidación total, la afirmación, por medio del eterno renacimiento del tejido cósmico de la comunidad.

Para tener paisajes vivos sanos y armónicos es necesario trabajarlos con constancia, oportunidad y dedicación. Parafraseando a Porfirio Enríquez (2005), se trata de cuidar el paisaje como si fuese una persona; acompañarlo (makichanalrunachana); acordarse de la Pachamama y celebrarla (Pachamama yuyariy), en este caso, celebrar los paisajes; vivir armoniosamente entre seres humanos y en la comunidad del runa (runapura allin kawsay) (Borja, 2009; 2012).

En consecuencia, los paisajes vivos son, están y tienen sentimientos. Por su complejidad, comprenden la percepción sinestésica de una ciudad como un todo unitario, e integran el conjunto de las relaciones espaciotemporales, sociopolíticas, económicas, culturales, afectivas, identitarias, simbólicas y comunicacionales. Los paisajes son criados en un proceso de crianza conjunta y son parte de quienes los habitan, trabajan, descansan en ellos, o los atraviesan; pero, ante todo, son hechos vivenciales, convivenciales, simbólicos, inseparables del runa.

6 Alberto Acosta (2013) considera el principio de Sumak Kawsay como el del buen vivir. Desde el movimiento indígena, cuyo aporte es fundamental al tema, Luis Macas (2014) considera que "El Sumak es la plenitud, lo sublime, lo excelente, lo magnífico, lo hermoso, lo superior. El Kawsay es la vida, es ser estando. Pero es dinámica, cambiante; no es una cuestión pasiva. Por lo tanto Sumak Kawsay sería la vida en plenitud. La vida en excelencia material y espiritual. La magnificencia y lo sublime se expresa en la armonía..." (p. 172).

7 Anidación, en el sentido "de una dimensión dentro de otra, protegida como en el nido de un ave. Una dimensión anidada se mueve junto con su dimensión mayor (padre) y puede configurarse para que herede la visibilidad del conjunto" (entrevista realizada por García en 2010). 
Por lo tanto, aprehender los paisajes vivos es plantear un problema metodológico, filosófico, paradigmático. Estudiarlos significa un reto a múltiples cuestionamientos y supone abrir el pensamiento para ver cómo los fenómenos se interrelacionan de manera compleja y continua dentro de la realidad social, con la finalidad de recuperar el barrio, la ciudad o el territorio.

\section{¿Por qué hablar de paisajes}

y de paisajes vivos?

La problemática particular de Quito y sus parroquias rurales requiere del reconocimiento de su diversidad, sus contradicciones y su complejidad como ciudad andina. Se trata de un abordaje difícil, pero necesario, dado el condicionamiento dominante de la cultura occidental. El desafío está en comprender y aprehender la diversidad cultural de un barrio de características singulares, en el contexto de la ciudad y en relación con el territorio.

La historia de segregación de los pueblos indígenas nos hace comprender las manifestaciones ancestrales como actos de resistencia que se han llevado a cabo a lo largo de más de quinientos años. Solo hasta las dos últimas décadas se han suscitado algunas transformaciones y procesos en el Ecuador, así como en otros países latinoamericanos, que han promovido el empoderamiento de los grupos sociales indígenas y llaman la atención sobre la diversidad étnicocultural del país. Los pueblos indígenas expresan que "el pachakutik ${ }^{8}$ está entrando y la ñaupa $a^{9}$ está asumiendo fuerza, y con eso es posible alcanzar un nuevo orden social de armonía y construir un pensamiento de lógica de convivencia de las sociedades culturales existentes" (Yampara, 1995, citado en Walsh, 2009, p. 18).

El barrio San Isidro de El Inca, de características populares y que alberga un grupo de población indígena originaria con manifestaciones culturales 'extrañas', a lo largo de la historia ha sido segregado de la ciudad. En la actualidad se ve a este sector como un obstáculo para el desarrollo ${ }^{10}$ del norte de la capital, más aún por tener una ubicación privilegiada. Los paisajes vivos existentes en el barrio son invisibles para las autoridades y los técnicos encargados de la planificación, pese a que existe un marco legal nacional que ampara los derechos de la cultura como patrimonio del pueblo ${ }^{11}$. Por lo general, la aplicación de las leyes de patrimonio cultural y natural no reflejan su contenido en los planes de acción y en el caso de la planificación urbano territorial local se ha convenido en la idea de una ciudad hipotética, en parte unitaria y uniforme, donde no hay cabida para realidades diferenciadas, pero al mismo tiempo segregada, ya que obedece a los intereses económicos de ciertos grupos de poder.

8 Pacha: vuelve o regresa; kutik: originar un orden distinto. El retorno de tiempos nuevos, en los cuales el espacio y el tiempo caminan, van y vuelven (Estermann, 1998).

9 Ñaupa: energía o un pasado capaz de renovar el futuro; fuerza que empuja y activa el pachakutik, que marcha desde adelante hacia atrás y viceversa, en forma de espiral (Walsh, 2009, p. 18)

10 Desde los años 50, la tendencia en América Latina ha sido erradicar todos los rezagos de lo ancestral para asumir una economía desarrollista, copia de los modelos de las sociedades industrializadas. En el caso específico de este barrio, la reubicación del aeropuerto Mariscal Sucre y su consecuente salida del sector norte de la ciudad de Quito está provocando cambios profundos en la respectiva reglamentación de uso de suelo y en el costo del mismo. Es posible que esto genere un proceso de gentrificación en el barrio.

11 En la Constitución del Estado ecuatoriano de 2008 consta el reconocimiento y respeto a las culturas. Las leyes sobre patrimonio cultural y natural se han promulgado desde 1978, la última es de 2007. La creación del Instituto Nacional del Patrimonio fue en 1978. Existe el reglamento de 1984, con modificaciones en 2007, 2008. En estas nuevas leyes y el reglamento está claro el reconocimiento del patrimonio intangible en el que constan las manifestaciones como las fiestas y rituales.

En el ámbito internacional las Naciones Unidas hace su declaración sobre los derechos de los pueblos indígenas en septiembre de 2007, en la que se expresa que los pueblos indígenas tienen derecho a mantener, controlar, proteger y desarrollar su patrimonio cultural, sus conocimientos tradicionales, sus expresiones culturales tradicionales y las manifestaciones de sus ciencias, tecnologías y culturas (Art. 11, 12 y 13). 


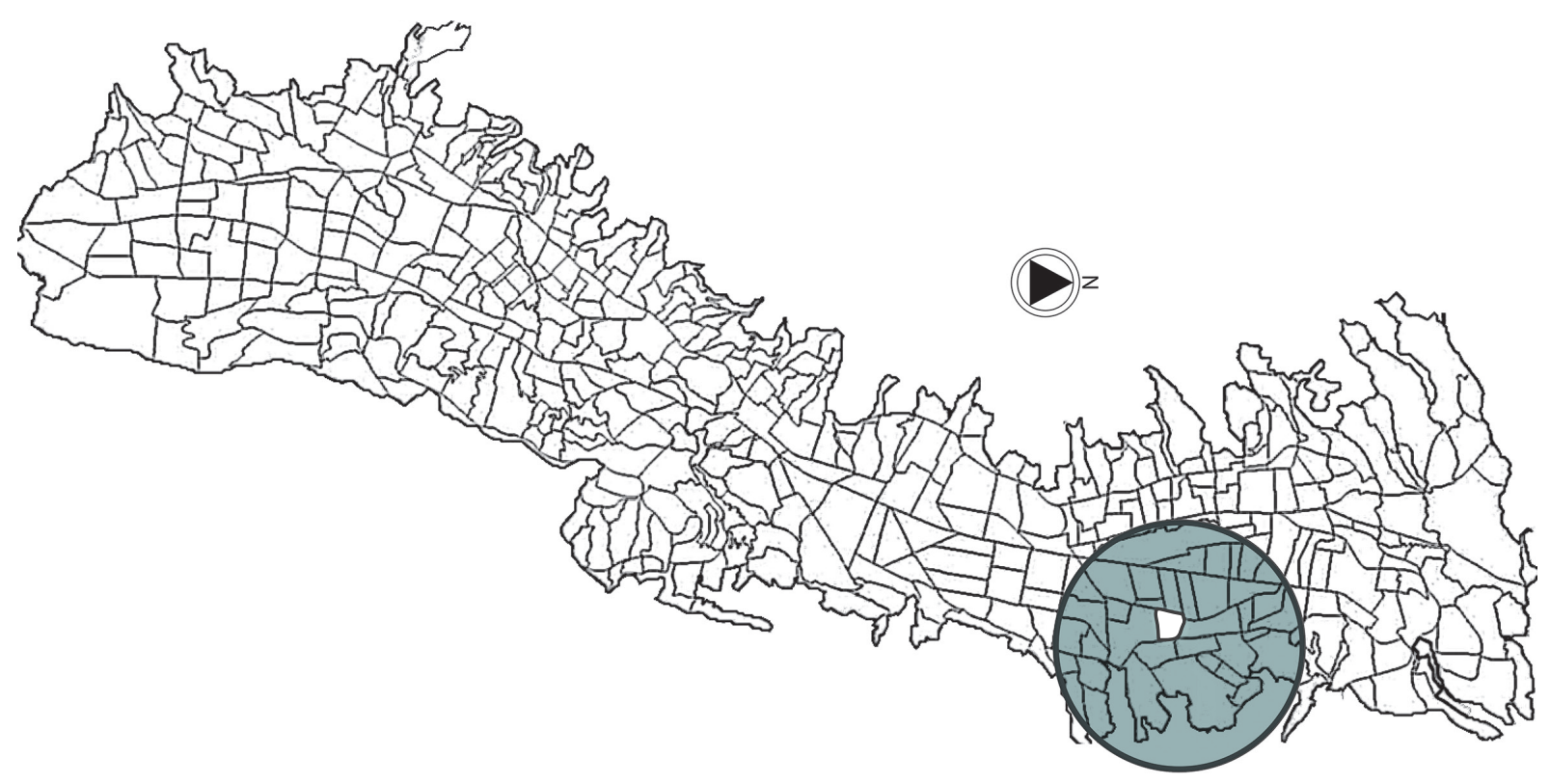

Fuente: elaboración propia

En el contexto global, cada vez se cuestiona más la 'racionalidad' que ha provocado una incontrolable explotación del planeta y el crecimiento y desarrollo vertiginosos de la mayoría de ciudades. Como dice María Victoria Martín:

La configuración actual del mundo global nos revela las tensiones producidas entre una lógica dominante de globalización uniformadora y teóricamente inevitable (la denominada globalización neoliberal) y una lógica del reconocimiento de la diversidad cultural y social existente, promovida en gran medida por los flujos migratorios y la transnacionalización de los medios de comunicación (Martín, 2009, citado en García, 2009, p. 242).

Estamos en un momento de gran crisis, los cambios ocurren precipitadamente, el 'progreso' se acelera, pero la calidad de vida de las personas disminuye y las diferencias entre los grupos sociales se incrementan; desaparecen las identidades locales y las relaciones afectivas con el lugar, el barrio y la casa. De ahí el interés por tomar la noción de paisaje con su carga afectiva, porque esta permite establecer puentes interculturales. Este es un concepto ha ido evolucionando, y se ha hecho más abierto, integral y relacional, especialmente en el ámbito de la geografía. Si bien, inicialmente estuvo asociado a la "mirada del observador", actualmente es muy utilizado con múltiples acepciones y en los más variados ámbitos.

Varios autores (Ojeda, 2009; Farina, 2006; Covarrubias, 1989 y Lynch 1960; 1992, entre otros) coinciden en que cabe interpretar el paisaje como un sistema de signos, para cuyo análisis es indispensable tomar en cuenta los significantes y los elementos simbólicos, de suyo íntimamente ligados a cualquier código de significación. En este sentido, los paisajes son signos, símbolos y señales que inciden en la lectura de la ciudad. Los mensajes emitidos por el paisaje posibilitan las 
relaciones afectivas de los ciudadanos con el medio, sus simbolismos y ritualidades.

El pensador contemporáneo Edgar Morin (1977) expresa que los conceptos deben ser vistos en sus múltiples interrelaciones, procurando descifrar más lo que emerge de ese conjunto que las partes indispensables. Por tanto, conceptos como cultura, hábitat y, en este caso, paisaje deben ser entendidos desde una visión sistémica, con una dinámica relacional que concibe el todo como un sistema complejo y organizado, en el que se evidencian y diferencian las partes.

En el pensamiento andino la relación afectiva con un ser vivo al que se debe cuidar y criar tiene otras implicaciones para los paisajes. Se trata de ideas que, en el contexto actual, trastocan las relaciones e interrelaciones tradicionales y demandan, además de un cambio en la forma de pensar, un abordaje interdisciplinar, pues escapan a lo puntual.

\section{Los paisajes andinos}

Definitivamente, introducirse en paisajes como los de San Isidro de El Inca implica abordar el mundo andino desde sus fiestas y ritualidades. En la concepción andina el espacio se entiende en el rito, el mito y las celebraciones (Nates y Pérez, 1997). Este barrio, con características similares a otros barrios populares de la urbe (arquitectura disímil, espacios públicos deteriorados y disminuidos, y mala calidad de los servicios), se caracteriza y diferencia por su dimensión simbólica y festiva. Esto ha contribuido a que, pese a las transformaciones sufridas y a las distintas maneras de criar $^{12}$ sus paisajes, resista en el tiempo y mantenga una identidad singular (Borja, 2012).

El concepto de lo andino es polisémico; originariamente tuvo que ver con el espacio geográfico de la región de los Andes, sus pisos ecológicos y su productividad a alturas inimaginables — hasta los 4.500 metros-, con un sistema denominado, por John Murra (1975), "control vertical de un máximo de pisos ecológicos”. En los Andes Septentrionales, por las características del ecosistema, los pisos ecológicos son de páramo y no de puno, como en Perú y Bolivia (Troll, 2010). Esta configuración geográfica posibilitó que las comunidades del norte estuvieran más próximas unas a las otras, y tuviesen un sistema de abastecimiento de productos diferentes. Disfrutaban de los diversos alimentos de la región esencialmente mediante grupos especializados en el intercambio, como los yumbos (Salomon, 1980; 1997), lo cual facilitó la promoción y el desarrollo de una compleja diversidad biológica y cultural, plasmada en sus paisajes y ritualidades.

Josep Estermann (1998) expone que el término andino se refiere "no solo a la región geográfica, sino a una categoría étnica, hablando de este modo del 'hombre andino' o del 'pueblo andino'. Esta característica se refiere [...] al ser humano que se siente identificado y arraigado en el ámbito geográfico, social y cultural andinos" (p. 53). A pesar de que se trata de varias y distintas culturas, con formas de organización, idiomas y expresiones artísticas propias, se puede entender lo andino como el común de manifestaciones culturales de esta región geográfica, con una forma de pensamiento de peculiar sensibilidad y organización categorial (Depaz, 2005).

En los emplazamientos originarios, los pobladores de estas regiones evidenciaban un sentido particular de hacer paisajes. Consideraban la selección del lugar de sus asentamientos en función de los elementos de la naturaleza: agua, cerro, fuego; determinaban la ubicación de sus espacios ceremoniales en relación con su cosmología; y 
tuvieron un especial cuidado en la disposición y forma de cultivar la tierra, que se mantiene hasta la actualidad. Se guardaba un profundo respeto al medio, no existía una desvinculación entre sujeto-objeto, sino una relación mágica, mítica, festiva con la naturaleza y el espacio. Había una unión entre $u k u$-pacha y kay-pacha, esto es, entre el mundo invisible y el visible.

Figura 3.

Paisaje andino Ingapirca

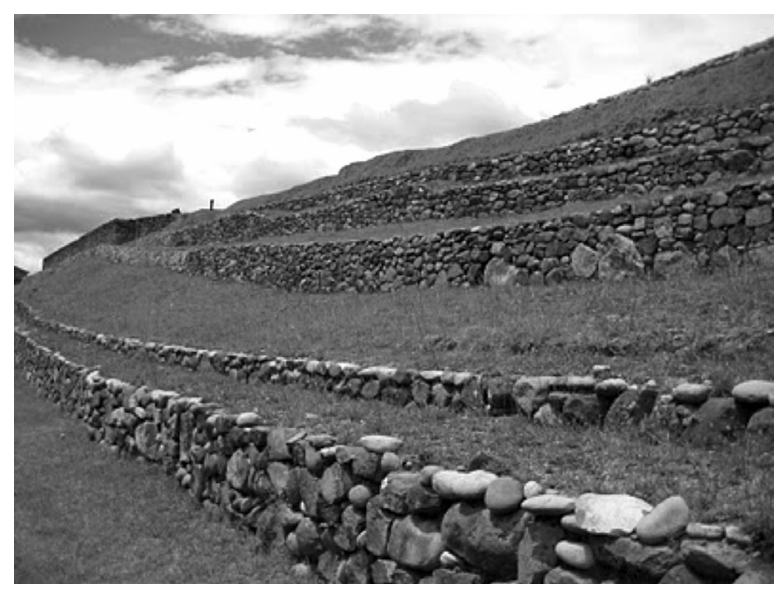

Fuente: Borja (2014)

Este es un paisaje vivencial que engloba y es parte de los cultivos, la gente, la naturaleza, los animales y los rituales. El ámbito geográfico andino se caracteriza por condiciones climáticas y topográficas extremas: calor en los valles, frío en la montaña, quebradas profundas y altiplanicies extensas, cumbres nevadas y valles tropicales, pero, además, variaciones de temperatura considerables de entre $4^{\circ} \mathrm{C}$ y $24^{\circ} \mathrm{C}$ en un mismo día.

En lo andino, al igual que en otras culturas — dada la topografía —, la dialéctica entre arriba y abajo cumple un papel preponderante. Esto ha originado fuertes relaciones entre los pueblos de arriba y los de abajo, como en el caso de los habitantes de Quito y su vinculación con los yumbos, habitantes de las tierras bajas. Estos hechos se recrean y celebran en la yumbada. Esta fiesta, como se mencionó al inicio, es un rito significativo para el barrio San Isidro de El Inca, así como para otras comunidades de la ciudad y de la Sierra Septentrional.

En ciertas comunidades indígenas aún se conserva el respeto ancestral por los elementos de la naturaleza en gestos como pedir 'permiso al cerro' antes de subir a una montaña, o en la necesidad de ofrendar y celebrar a la Pachamama con las fiestas y los ritos anteriores a la siembra o a la construcción de una casa. Se tiene una idea vivencial del espacio que tiene que ver con los sentimientos y no con la "mirada del observador". Se trata de una manera diferente de abordar la vida. En muchos casos estos principios han sido olvidados por las propias comunidades, y más aún en la ciudad. Para su comprensión y recuperación se requiere una revisión de las formas de pensar actuales.

\section{Cambiar la forma de pensar}

Para abordar la problemática de los paisajes vivos es necesario recurrir no solo a una nueva forma de pensamiento sino a un nuevo paradigma ${ }^{13}$. Hace falta asumir un pensamiento que implique el respeto a las diferencias, la coexistencia de diversas racionalidades en lo analítico, dialéctico, fenomenológico, estructural y hermenéutico. En este sentido, la interculturalidad, como forma de pensamiento, permite el movimiento entre los dos mundos, el de Occidente y el del mundo andino. Un paradigma que posibilite reconocer, respetar y articular las diferencias culturales, e incluye las experiencias colectivas, como,

13 "Un cambio de paradigma es revolucionador. Una revolución que afecte a un gran paradigma modifica los nuclei organizadores de la sociedad, la civilización, la cultura y la noosfera. Es una transformación del modo de pensamiento, del mundo del pensamiento y del mundo pensado. Cambiar el paradigma es a la vez cambiar de creencia de ser y de universo" (Morín, 1992, p. 237). 
en este caso, la cosmovisión Abya-Yala ${ }^{14}$, marco fundamental de los paisajes vivos. Es imprescindible tomar los aspectos de las culturas no como opuestos sino como complementarios.

En el Ecuador, la propuesta de la interculturalidad acompaña el proceso de autodefinición de los pueblos indígenas, y en la actualidad es la bandera de lucha que acoge a otras minorías sociales ${ }^{15}$. En este sentido, la interculturalidad puede ser entendida como un proceso permanente de construcción de una interrelación respetuosa entre personas, grupos, conocimientos, valores y tradiciones distintos. "Intenta romper con la historia hegemónica de una cultura dominante y otras subordinadas y, de esa manera, reforzar las identidades tradicionalmente excluidas para construir, tanto en la vida cotidiana como en las instituciones sociales, un con-vivir de respeto y legitimidad entre todos los grupos de la sociedad" (Walsh, 2009, p. 41). Como plantea Boaventura de Sousa Santos (2005): “Tenemos el derecho a ser iguales cuando la diferencia nos inferioriza, tenemos el derecho de ser diferentes cuando la igualdad nos descaracteriza” (p. 131).

Según el pensamiento andino, como señala Jorge García, se trata de criar la interculturalidad, que tiene que ser co-generada y co-construida, de manera complementaria, recíproca, proporcional y correspondiente, al igual que con los seres humanos (García, 2009). El pensamiento andino, o racionalidad ${ }^{16}$ Abya Yala, está vigente. Según
Estermann, tiene sus propios mitos fundantes (no logocentrismos), su propio modo englobante de concebir la realidad y de entender los fenómenos; un esquema de pensamiento muy particular; una manera de representar el mundo relacional y vivencial que se diferencia del orden occidental. Esta racionalidad, concepto debatido interculturalmente, no hace referencia específica a la "razón"; por ello se puede hablar de racionalidades en plural, "pues estamos usando un concepto 'trans-cultural y trans-epocal"'17 (Estermann, 1998, p. 88).

La base del pensamiento andino es la interconexión de las partes y el todo. La relacionalidad es el concepto clave, referente más a la idea de interrelacionalidad que a la de holismo. El mundo es visto como una red de relaciones que "tiene carácter sapiencial, conoce y manifiesta su saber en la crianza, el ritual y la celebración" (Depaz, 2005 , p. 57). Esta visión comprende las relaciones entre los "elementos que conforman la totalidad: Hanan Pacha (o mundo de arriba), Kay Pacha (mundo inmediato, donde estamos) y Ukuy Pacha o Urin Pacha (abajo, mundo subyacente); íntimamente relacionados entre sí, son seres animados que se complementan, relacionan y autorregulan" (García, Lozano, Olivera, y Ruíz, 2004, p. 165). La relacionalidad se comprende o se desagrega en los siguientes principios: de correspondencia, de complementariedad o karywarmikay ${ }^{18}$, vivencial-simbólico ${ }^{19}$, y de reciprocidad o ayni ${ }^{20}$.

\footnotetext{
14 Abya Yala: expresión del pueblo Kuna (Panamá) que significa “tierra en plena madurez". Se utiliza para designar a los territorios americanos (López, 2004).

15 En la nueva Constitución del Ecuador de 2008 en el Artículo 1, expresa textualmente: "El Ecuador es un Estado constitucional de derechos y justicia social, democrático, soberano, independiente, unitario, intercultural, plurinacional y laico", así como se reconoce el principio sumaq kawsay como eje fundamental, sin embargo aún dista mucho que se aplique y sea una realidad.

16 Existe un debate respecto a la utilización del concepto de racionalidad para el reconocimiento de la forma de pensamiento andino como tal. Josef Estermann (1998) sustenta, desde una visión intercultural, que la racionalidad de una cultura se manifiesta, sobre todo, de una manera pragmática, y que el análisis de sus interacciones nos permite inferir los mitos fundantes de su racionalidad.

17 "[...] un cierto 'modo de concebir la realidad', una 'manera característica de interpretar la experiencia vivencial', un 'modo englobante de entender los fenómenos', un 'esquema de pensar', una 'forma de conceptualizar nuestra vivencia', un 'modelo (paradigma) de (re-) presentar el mundo'” (Estermann, 1998, p. 88).

18 Kary-warmi: hombre-mujer. Los opuestos resultan ser complementarios y no contradictorios (kari-warmi, chiri-cunu, tuta-puncha, entre otros) (García et al., 2004, p. 166).

19 Hace referencia a mitos fundantes, festividades, gestualidad, lenguaje simbólico y lugares sagrados, íntimamente relacionados entre sí y con las actividades cotidianas (García et al., 2004)

20 Implica una correlación entre dos "campos" de la "realidad" (Estermann, 1998, p. 123).
} 
El principio ayni permite al runa los intercambios, dones y favores, factores fundamentales para vivir en completo equilibrio con la naturaleza y los demás seres humanos. La expresión que resume el ayni en el mundo andino es: "Primero hay que dar para recibir" (Depaz, 2005, p. 167). Milla cita a la comunera Hilaria Supa, quien lo explica así:

Es la ley más útil para la vida diaria. Tal como se practica entre comuneros, también funciona entre seres humanos y la Pachamama y los Apus. Los pagos a la Pachamama son como devolver el ayni que ella nos da mediante las plantas silvestres y cultivadas que nos alimentan y curan (p. 151).

Es importante anotar que esta relación no se centra en dos individuos, sino en la comunidad y en cada uno de sus miembros. El runa se da a los otros y recibe de los demás: es un ser para sí y un ser para otro. "Con el ayni trabaja y con la mink'a (trabajo comunitario sin remuneración) goza; con la wayka (fuerza) muestra su fuerza poderosa de colectivo" (Mejía, 2005, p. 96). Estos principios se expresan en la chakana, conocida también como cruz andina, puente cósmico articulador de los diversos elementos de la unidad que permite establecer una compleja trama de relaciones entre las partes y el todo. Consiste en una "densa red de redes que se coproducen, que son constitutivas de la compleja trama de acontecimientos que en su conjunto definen la densidad, diversidad, textura, del conjunto" (García et al., 2004, p. 15). Por medio de la chakana se exploran categorías como la emoción relacional, la intuición iluminadora y la generación de espacios de sentido simbólico.

La chakana es una cruz de orden quinario que representa la unidad de la diversidad, mantiene una permanente tensión de correspondencia, complementariedad y reciprocidad entre sus diversos componentes. Está inscrita en un cuadrado, implica la cuadratura de un círculo, pero, a su vez, puede ser volumétrica, tiene ejes claros de orientación y relacionalidad. Esta cruz conserva en su centro el momento articulador y dinámico: la chalana. La forman cinco componentes: el yachay (saber), el munay (amar), el ruray (hacer) el ushay (poder) y el kawsay (origen-vida) (García et al., 2004, p. 15).

Figura 4

Cruz andina o chakana

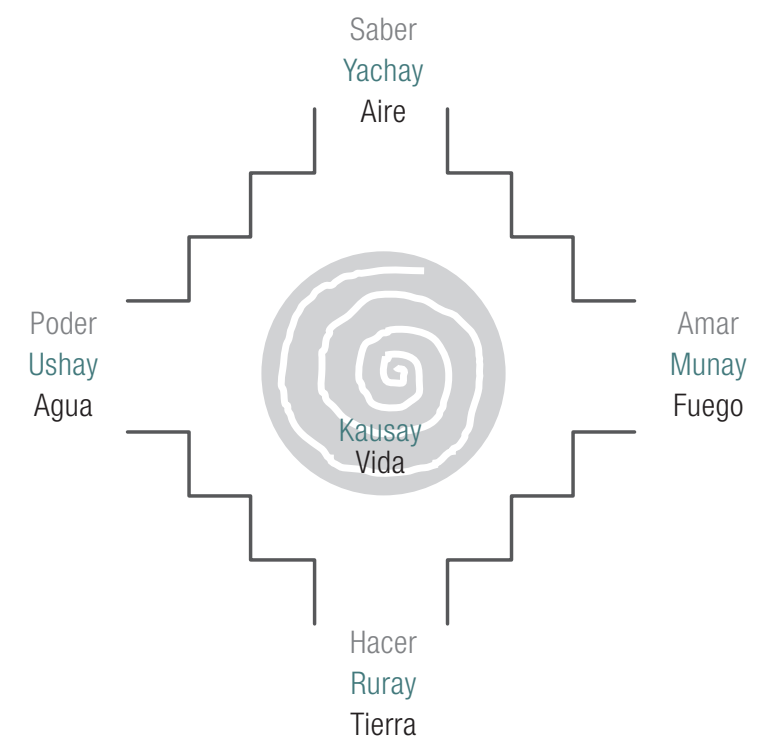

Fuente: García (2009)

La realidad está presente en forma simbólica más que en forma representativa o conceptual. Se la concibe como soñada y, por medio del sueño, se recrea, revela y co-construye. "Esta co-construcción de la realidad se da en lo festivo-celebrativo, en donde se hace más intensa, más vital, más vivencial" (García et al., 2004, p. 16). Esta es la esencia del aprendizaje vivencial.

\section{Hacia el aprendizaje vivencial}

La relación del runa con la comunidad, el territorio, la tierra y el hábitat, cuyos mecanismos predilectos son la ritualidad, el baile, el arte, el 
culto. La parte festivo-celebrativa que teje relaciones desde las emociones estéticas es el aprendizaje vivencial. Lo importante para el indígena es cómo vive los hechos, no su explicación ${ }^{21}$. La armonía del mundo se construye sobre la emoción, el afecto y la amistad. En el mundo urbano esto se expresa en el reconocimiento de que cada comunidad y cada barrio son diversos, pues cada uno tiene una manera de saber hacer sus caminos, pero lo importante es configurar estas relaciones de cariño cuyay ayllu, que son las familias que se tienen mucho apego y cariño entre sí.

De ahí la importancia de comprender lo que significa criar, cuyo equivalente en quichua es $u y w a^{22}$. Se usa la misma expresión para lo criado. Es un verbo que expresa "mutualidad y amparo" (Rengifo, 2009) y sentido de reciprocidad, porque al criar, lo criado nos cría. Según Juan Van-Kessel (1992), todos somos criadores y criados al mismo tiempo, en un proceso de co-crianza. Es un pensamiento "seminal", como lo afirma Rodolfo Kusch (1970), quien siguiendo el modelo de los procesos biológicos dice que: los acontecimientos "se dan" como en el reino de la flora y la fauna. En consecuencia, hacer el bien a la comunidad es hacerse bien a uno mismo; criar bien la montańa solo puede traer beneficios. Procurar, por ejemplo, obtener mejores pastos para mejorar el ganado, a la vez, proporciona mejores productos; criar bien el río resulta en mejores aguas $y$, por ende, mejores peces, regadíos y cultivos. Todo esto repercute directamente en la bonanza del ayllu y, por tanto, en la crianza de los paisajes.

En la concepción indígena, la tierra, llamada Pachamama, es divina y es la madre universal de la vida (Kusch, 1970 y Van-Kessel y Condori, 1992). Al proceso de crianza de la vida se lo llama makichana ${ }^{23}$ (hacer con la mano) (Enríquez, 2005). Este término comprende un profundo contenido, una visión y una experiencia del runa (ser humano) respecto a su labor agropecuaria, pero al mismo tiempo tiene un significado metaempírico y metafórico, pues también se entiende como ritual y celebración. Por lo mismo, la labor relacionada con la crianza de la vida en la chacra implica dos tipos de actividades y cuidados: empíricos y simbólicos.

En síntesis, se trata del aprendizaje que se logra en la relación con la vida, el suelo, el ambiente y los otros, desde una práctica simbólica. Dentro del ámbito urbano implica una relación festivo-celebrativa con la ciudad, el barrio, la calle, la plaza, el paisaje y el territorio. Aquí los runas (ciudadanas y ciudadanos) se sienten parte de la realidad, y "la realidad' se revela como un conjunto 'holístico' de símbolos significativos para la vida cotidiana” (Estermann, 1998, p. 94). Por esta razón, la propuesta de ir hacia el aprendizaje vivencial de los paisajes vivos conlleva recuperar la emoción estética del lugar, la construcción conjunta de una realidad.

\section{Conclusiones}

La apuesta por el análisis de los paisajes vivos permite la construcción de puentes entre las culturas indígena andina y mestiza occidental. Desde esta perspectiva, se pueden aprehender los paisajes diferentes, es decir, aquellos que contienen las relaciones afectivas y simbólicas de esta población con la Pachamama (la Tierra) y su pacarina (lugar de sus ancestros), expresadas en ritos y mitos que son parte de la crianza de la vida.

\footnotetext{
21 "Se vive en un mundo donde el atributo del saber no es exclusividad del ser humano: saben también la naturaleza, el paisaje, las deidades, es decir, la gran familia que es el ayllu" (Rengifo, 2009, p. 56).

22 Uyway: criar y educar a los propios hijos o a los animales domésticos (Diccionario quechua-aymara al español).

23 Maki 'mano', el factivo /cha/ y el instrumentalizador /na/: "hacer con la mano" (Enríquez, 2005, p. 73).
} 
Estos resquicios de los paisajes vivos armónicos existentes posibilitan identificar un barrio o una parroquia como tal, así como las distintas dimensiones puestas en escena durante sus fiestas, no solo aspectos étnicoculturales, sino, precisamente, su resignificación en el nuevo contexto urbano. Pero la disputa de estos habitantes por su subsistencia, y por ganar un espacio en la ciudad contemporánea, tiende a hacerles desaparecer.

Los hechos vivenciales (desde el pensamiento andino) constituyen un elemento esencial de la problemática urbana contemporánea; sin embargo, en la ciudad de Quito, y en otras urbes latinoamericanas, no son tomados en cuenta en su importancia. Por ello, cabe abordar dicha cuestión a partir del análisis de los paisajes por medio de relaciones interculturales. Esto provoca la integración de distintos tiempos de historia y características diferenciadas entre el pasado y el presente, articulados en varios órdenes: lo urbano, lo social, lo cultural, lo político, lo económico y lo simbólico-festivo. Por tanto, permite descifrar los paisajes simbólicos y vivenciales que emergen con ese sentido de la ñaupa (energía que empuja hacia el pachakutik), considerando que un pasado es capaz de renovar el futuro.

El solo hecho de enunciar estos temas, de ponerlos sobre el tapete, puede llevar a los y las profesionales que participamos directamente en la construcción de la ciudad, y a sus habitantes, hacia un cuestionamiento capaz de poner en marcha un proceso encaminado a vivir la ciudad como parte de uno mismo, que permita "pensar con el corazón y querer con la cabeza” (García, 2010), recuperar la memoria, recrear los mitos y los ritos, aprender y abrir los sentidos. La meta final es compartir el sumak kawsay (vivir en armonía o buen vivir) con uno mismo, con los semejantes (runas), con la naturaleza (sallqa) y con las deidades (waka), y que estas reflexiones incidan en las autoridades de los gobiernos locales y nacionales con la finalidad de tener políticas y acciones más justas.

Saskia Sassen (2011) nos dice que en estos momentos de crisis es cuando otras perspectivas de análisis y propuestas afloran: que los agujeros negros se activen en algo positivo, y que todas las epidemias negativas vividas de manera global y local se reviertan en positivas. Como plantea Alberto Acosta (2013), la crisis actual nos lleva a considerar los derechos de la naturaleza, y por qué no de los paisajes. Es tiempo de plantear alternativas desde lo local, que nos permitan recuperar la idea de la vivencialidad y del "lenguajear" (Maturana, 2006) entre los seres humanos, pero también con el paisaje, el ambiente y la vida, de una manera festiva, celebrativa. Es preciso recuperar o reavivar los principios de la relacionalidad: la complementariedad, la correspondencia, lo vivencial simbólico y, especialmente, la reciprocidad (ayni), para recuperar los paisajes vivos en nuestras ciudades, no como una idea romántica, sino como algo aplicable a los tiempos actuales.

En este sentido, en la Facultad de Arquitectura, Diseño y Artes de la PUCE hemos creado el Laboratorio de los Paisajes Vivos, basándonos en estos principios para apoyar a comunidades vulnerables en sus procesos identitarios. Partimos de la idea de que si no nos reconocemos es difícil defender nuestros derechos. La propuesta incluye el trabajo participativo para el mejoramiento de la calidad de vida, en forma de proyectos comunitarios e individuales. El objetivo es recuperar la emoción estética por el lugar, celebrar donde cada uno vive, y generar un continuo aprendizaje vivencial de los espacios para mejorar la calidad de vida. Para ello se trabaja con los habitantes de barrios y parroquias y, además, con las organizaciones públicas que se relacionan con la problemática para incidir directamente en la toma de decisiones sobre los paisajes, el hábitat y el territorio de estas comunidades. 
Esta propuesta comprende un nuevo enfoque, que no excluye otras perspectivas de estudio realizadas sobre el tema urbano en el país, y en otros contextos. Existen diversas aproximaciones sobre la necesidad de concebir de manera distinta a las ciudades, de recuperar la calidad de vida, cada una con su particularidad ${ }^{24}$.

En este caso, el hecho de que estas reflexiones nacen de una realidad vivida en un barrio de una ciudad andina como Quito, y que, además, deja un camino abierto para proseguir en esta línea de investigación y actuación, es lo relevante.

\section{Bibliografía}

Acosta, A. (2013). Buen vivir. Sumak Kawsay, una oportunidad para imaginar otros mundos. Barcelona: Icaria.

Augé, M. (1992). Los no lugares, espacios del anonimato. Barcelona: Gedisa.

Borja, K. (2009). Paisaje vivo. Análisis del paisaje urbano de San Isidro de El Inca. En T. Del Valle. (coord.), Actas del XVII Congreso de Estudios Vascos: Gizarte aurrerapen iraunkorrerako berrikuntza. Innovación para el progreso social sostenible. (pp. 513-537). Donostia: Vitoria-Gasteiz. Eusko Ikaskuntza.

Borja, K. (en prensa). Grado Cero: la condición equinoccial y la producción de cultura en el Ecuador y otras longitudes ecuatorianas. Los paisajes vivos del equinoccio: la yumbada de San Isidro de El Inca. En E. Ponce. Grado Cero: la condición equinoccial.
Borja, K. (2012). Criar paisajes vivos. Una manera de aprehender los paisajes urbanos andinos. El caso de San Isidro de El Inca. (Tesis doctoral inédita). Universidad del País Vasco, Donostia.

Covarrrubias, X. (1989). El delito de la contaminación visual. Ciudad de México: Universidad Autónoma Metropolitana-Azcapotzalco.

De Sousa, B. (2005). Foro social mundial: manual de uso. Barcelona: Icaria.

Depaz, Z. (2005). Horizonte de sentido en la cultura andina. Comunidad, (5), 47-76.

DMQ. (2008). Ordenanza 260-Areas y bienes patrimoniales. Recuperado de http://www7.quito. gob.ec/mdmq_ordenanzas/Ordenanzas/ORDENANZAS\%20A\%C3\%91OS\%20ANTERIORES/ORDM-260\%20-\%20AREAS\%20Y\%20 BIENES\%20PATRIMONIALES.pdf

Enríquez, P. (2005). Cultura andina. Puno: Altiplano.

Estermann, J. (1998). Filosofía andina. Quito: Abya-Yala.

Farina, A. (2006). Il paesaggio cognitivo. Milán: Franco Angeli.

García, J. (2009). Interculturalidad de las interculturalidades: reflexiones en el camino. Publicación del Seminario para la construcción de politicas públicas interculturales. Seminario llevado a cabo por el Ministerio Coordinador del Patrimonio, Ecuador.

García, J., Lozano, A., Olivera, J. y Ruíz, C. (eds.). (2004). Aprender en la sabiduría y el buen vivir. Quito: Uinpi.

24 Solo por citar unos pocos ejemplos: Yin Fu Tuan (2007) trabaja sobre la topofilia, y rescata al amor por el lugar; Ana Patricia Noguera (2004) expone sobre el reencantamiento por el lugar desde un enfoque ambiental; Marc Augé (1992) nos habla de los lugares y no lugares, desde su significación. 
Illich, I. (1978). La convivencialidad. Morelos: Ocotepec.

Jara, H. (2007). Tulipe y la cultura yumbo. Arqueología comprensiva del subtrópico quiteño. Quito: Fonsal.

Kusch, R. (1970). El pensamiento indigena americano. Puebla: Editorial José M. Cajica.

López, M. (2004). Los senderos de Abya-Yala. Quito: Abya-Yala.

Lynch, K. (1992). Administración del paisaje. Bogotá: Norma.

Lynch, K. (2000). La imagen de la ciudad. Barcelona: Gustavo Gili.

Macas, L. (2014). Sumak Kawsay. La vida en plenitud. En A. Hidalgo, A. Guillén y N. Deleg. (eds.), Sumak Kawsay Yuyay. Antología del pensamiento indigenista ecuatoriano sobre Sumak Kawsay. (pp. 169-176). Huelva: Centro de investigaciones en Migración.

Martín, M. (2009). Conocimientos "otros", nuevas formas de transgresión de las geopoliticas del conocimiento desde el paradigma de la interculturalidad. Madrid: SEPHA.

Maturana, H. (2006). ¿Qué es educar? Recuperado de http://matosas.typepad.com/educar_ juntos/2008/02/qu-es-educar1-d.html

Mejía, M. (2005). Las categorías quechuas como fundamento para una filosofía peruana y de América Andina. Lima: Amaro.

Milla, C. (2002). Ayni, introducción a la paleosemiótica. Lima: Asociación Cultural Amaru Waira.

Morin, E. (1977). El método. Tomo I. Madrid: Cátedra.
Murra, J. (1975). Fomaciones económicas y politicas en el mundo andino. Lima: Instituto de Estudios Peruanos.

Naciones Unidas. (2007). Declaración de las Naciones Unidas sobre los derechos de los pueblos indigenas. Recuperado de Declaración_Naciones_Unidas_Derechos_Pueblos_Indígenas.doc

Nates, B. y Pérez, B. (1997). Los andares de la memoria en la construcción andina del espacio. Politica y Sociedad, (25), 135-150.

Noguera, A. (2004). El reencatamiento del mundo: ideas para una ética-estética desde la dimensión ambiental. Recuperado de http://www.bdigital.unal. edu.co/5963/2/9687913312.pdf

Ojeda, J. (noviembre, 2009). Ponencia-relatoría: el paisaje, memoria de los territorios. Ponencia presentada en XVII Congreso de Estudios Vascos, Donostia, Universidad del País Vasco.

Rengifo, G. (septiembre, 2009). Cosmovisión y producción de conocimientos en el medio andino amazónico. Revista pensamiento pedagógico, (12), 54-58.

Salomon, F. (1980). Los señores étnicos de Quito en la época de los incas. Otavalo: Instituto de Antropología de Otavalo.

Salomon, F. (1997). Los yumbos, niguas y tsatchilas o "colorados" durante la colonia española: etnohistoria del Noroccidente de Pichincha, Ecuador. Quito: Abya-Yala

Sassen, S. (6 de mayo de 2011). Saskia Sassen en el MARQ de Buenos Aires. Recuperado de www. youtube.com/watch?v=roHmHrqGFMA

Troll, C. (2010). Ecología del paisaje. Investigación ambiental, 2(1), 94-115. 
Tuan, Y. (2007). Topofilia: un estudio de la percepción del medio, actitudes y valores sobre el entorno. Santa Cruz de Tenerife: Melusina.

Van-Kessel, J. y Condori, D. (1992). Criar la vida: trabajo y tecnología en el mundo andino. Santiago de Chile: Vivarium.

Walsh, C. (2009). Interculturalidad, estado, sociedad. Luchas (de) coloniales de nuestra época. Quito: Abya-Yala.

Yampara, S. (1995). Pachakutti-Kandiri en el paytiti. Reencuentro entre la búsqueda y retorno a la armonía originaria. La Paz: Qamañpacha CADA. 